Article

\title{
Position Control with ADRC for a Hydrostatic Double-Cylinder Actuator
}

\author{
Bin Wang *, Hengyu Ji and Rui Chang \\ Jiangsu Province Key Laboratory of Aerospace Power System, College of Energy and Power Engineering, \\ Nanjing University of Aeronautics and Astronautics, 29 Yudao St., Qinhuai Dist., Nanjing 210016, China; \\ jhynuaa@163.com (H.J.); crnuaa@163.com (R.C.) \\ * Correspondence: binwang@nuaa.edu.cn
}

Received: 30 September 2020; Accepted: 5 November 2020; Published: 9 November 2020

\begin{abstract}
A compact and flexible hydraulic double-cylinder actuation scheme is proposed for use in applications, especially where power density is extremely demanding. In view of flexible amounting requirements, long and thin hoses were utilized to connect two cylinders. Affecting the actuation preciseness, volume variation of the hoses caused by pressurized oil and bubbles was the main problem the system encountered. In this study, an active disturbance rejection control (ADRC) strategy was adopted for the improvement of displacement control performance under uncertain external load. After the experimental verification of the necessity of a hose model for the system, a centralized-parameter hose model was constructed where the coefficients are determined on the basis of the experimental data. Additionally, the system and the controller proposed were mathematically modeled. Simulation results shows that the system using ADRC exhibited higher displacement accuracy and better dynamic performance than that using PID (Proportion-Integral-Derivative) or fuzzy PID. ADRC has a stronger disturbance rejection ability. ADRC is an effective solution to nonlinear control of systems with uncertain parameters or various loads.
\end{abstract}

Keywords: hydraulic cylinder; active disturbance rejection control; displacement control; nonlinear disturbance

\section{Introduction}

Due to small size, light weight, fast response and high accuracy, the electrohydraulic servo system has been widely used in many fields such as aerospace, robot, construction industry, etc. [1,2]. At present, hydraulic actuation mainly includes valve-controlled and pump-controlled schemes. The valve-controlled system has been widely used in engineering fields owing to its high response frequency and power-to-weight ratio [3]. Pump-controlled EHA (Electrohydrostatic Actuator) provides a sleeker and cleaner way to produce hydraulic power with higher energy efficiency $[4,5]$. However, hydraulic actuators used in aerospace are inevitably strict in size and weight. They involve an oil supply source, which is a weight burden. A hydraulic actuation system without an oil source is obviously advantageous in aerospace application.

To break through the restriction, alternative methods have been investigated to affordably improve system efficiency. Minava presented a direct-driven hydraulic system without conventional oil source [6], which combined advantages of power density of hydraulic system and accuracy of electric motor system, and studied the application of direct-driven hydraulic device in trackless mobile machinery. A speed and position control system using double cylinders adopted a hydraulic accumulator instead of conventional oil tank, and an electric motor was used to achieve closed-loop control [7]. Effects of different parameters on dynamic characteristics of hose were examined. The smaller the hose flow diameter is, the more sensitive the volume variation to the pressure is [8]. 
Therefore, it is extremely necessary to model the hose in small-size and high-pressure displacement control systems.

Many research studies on position control of the electrohydraulic actuator were conducted, some of which reveal how external and internal nonlinear factors affect the control accuracy and system robustness $[9,10]$. Due to simple structure and easy implementation, PID control has been commonly used in hydraulic systems $[9,10]$. On this basis, some researchers developed accurate fuzzy PID and PSO-PID controllers [11-14]. A robust fixed-gain linear output pressure controller was designed for a double-rod electrohydrostatic actuator using quantitative feedback theory (QFT) to provide desired transient responses, tracking bandwidth, robust stability, and disturbance rejection for the closed-loop system [15]. Erik used model predictive control to eliminate the influence of feedback controller performance and to integrate both actuator limitations and other necessary constraints on dynamic wheel-load variation and suspension travel [16]. A nonlinear PI position controller was developed for the EHA to achieve the accurate positioning requirement of position-based impedance control (PBIC). The controller compensated for the adverse effect of stiction, and a high position accuracy was attained [3]. A novel sliding mode control (SMC) design framework was devoted to providing a favorable SMC design solution for the position tracking control of electrohydrostatic actuation system (EHSAS). The chattering was effectively attenuated, and the mismatched disturbance was satisfyingly compensated [17]. A novel discrete-valued model predictive control (DVMPC) algorithm was proposed for position control of a pneumatic cylinder [18]. A linear extended state observer (LESO) was adopted to achieve real-time estimation of the unmeasured system states and matched disturbance, and a nonlinear disturbance observer (NDO) was used to estimate the largely unknown mismatched disturbance at the same time [19]. All of the above concluded that a good control strategy is critical to the stability and robustness of position control.

ADRC is not predicated on an accurate and detailed dynamic model of a plant, and is extremely tolerant to uncertainties [20-22]. At present, ADRC has been applied in many fields, including artificial blood pumps, air-fuel ratio control in gasoline engines, airship horizontal trajectory tracking control, PV (Photovoltaic)-wind energy conversion system and aircraft electro-mechanical actuators [23-26]. The robotic system was represented as a linear perturbed system whose lumped disturbance input is estimated and then compensated by an extended state observer-based control [20]. ADRC has attracted attention and application in position control.

In this study, an electric motor was used as the original power component for hydraulic actuator without an oil tank. The motor rotates the ball screw, which pushes the power cylinder to pressurize the oil between the two cylinders and then moves the target cylinder. Considering installation and maintenance for an extremely narrow space, the slender hose was employed to connect these two cylinders for the flexibility required. Expansion of the hose induced nonlinear displacement of the cylinder. This paper focuses on the active disturbance rejection control strategy for a hydrostatic double-cylinder actuator, which was systematically analyzed and compared with the conventional PID and fuzzy PID strategy. Then, advantages of ADRC are verified. ADRC consists of a tracking differentiator (TD), extended state observer (ESO) and nonlinear state error feedback control law (NLSEF). TD achieves smooth approximation to the generalized derivative of input signals. ESO estimates the output and the total real-time perturbation. NLSEF uses the total perturbation observed by the ESO to generate the control variables, so as to ensure the stability of the system. This can provide a theoretical basis for ADRC application in double-cylinder hydraulic actuators. Section 2 describes the principle and mathematical model of the system. An ADRC strategy was designed. In Section 3 , the results are revealed. Concluding remarks are presented in Section 4. 


\section{System Principle and Mathematical Model}

\subsection{System Principle}

Figure 1 is a schematic diagram of the double-cylinder actuator. The electric motor rotates according to a pulse input and its angular displacement is transformed into linear displacement by a ball screw. The power cylinder pressurizes the oil in one chamber to push the target cylinder forward. A transducer is arranged to measure the displacement of the target cylinder. If these two cylinders are identical, their motions are theoretically synchronous. Actually, due to the deformation of the pressurized chamber, it is ineluctable for the cylinder leakage and the oil bulk modulus change caused by pressure or air. Size of the target cylinder can be designed as small as possible to be accommodated in designated space. In order to investigate the system performance under possible loads, an electrohydraulic system was fabricated as external load simulator. It mainly consisted of oil source, a proportional servo valve, a loading cylinder and a force transducer. A force closed-loop circuit ensured production of the required load exerted on the target cylinder. The flexible hose connection between two cylinders allows the system to be suitable for narrow space, and it can separate the target cylinder from the driving and control part for flexible assembly and disassembly. Moreover, the oil source was removed, simplifying the system structure greatly.

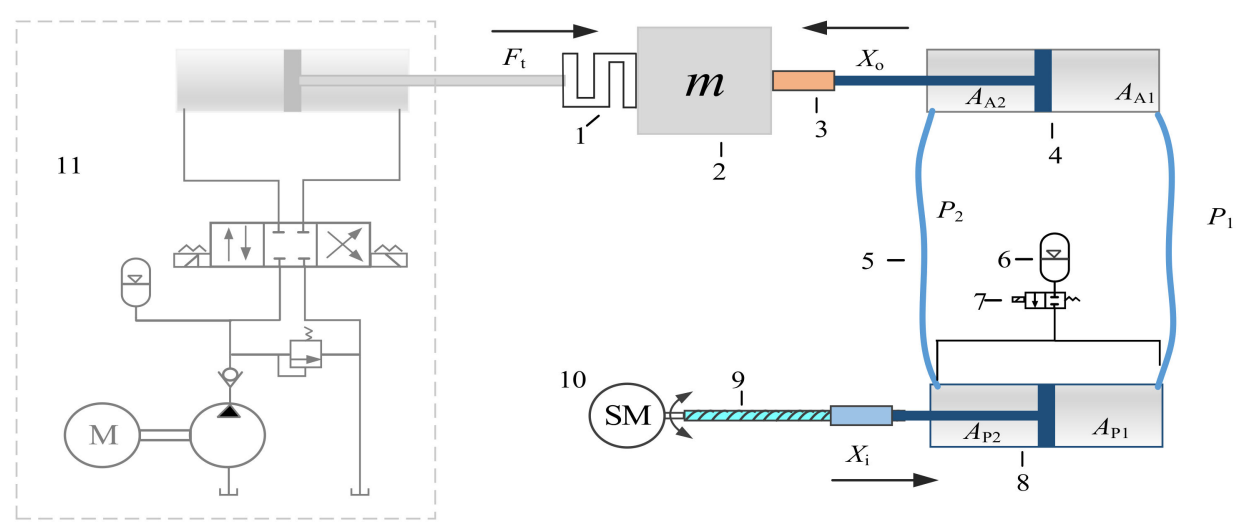

Figure 1. Schematic diagram of the whole system. 1. Force transducer; 2. Load mass; 3. LVDT; 4. Target cylinder; 5 . Hose; 6 . Accumulator; 7. On/off valve; 8. Power cylinder; 9. Ball screw; 10. Stepping motor; 11. Loading system.

\subsection{System Mathematical Model}

The hose was one of primary factors affecting the actuator performance. It was modeled by the centralized parameter method [27], and the pressure and the flow rate in the hose can be equivalent to the voltage and current in electric circuit. The model based on this method is shown in Figure 2. Here $R$ and $L$ stand for the resistance and the inertia of the oil, respectively, and $C$ describes the characteristic of the pressurized oil and the hose deformation.

$$
C\left(p-p^{\prime}\right)=q-q^{\prime}
$$

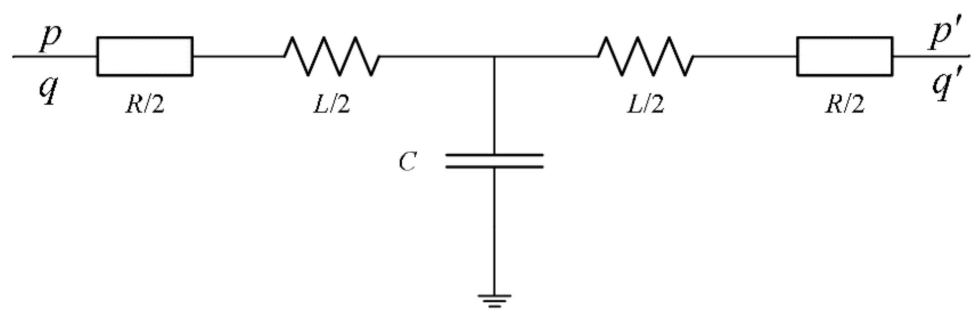

Figure 2. Hose model. 
Generally, the hose has much larger expansion than the pipe if filled with high pressure oil. When modeling the hose, both the static and dynamic variation caused by the pressure and the viscoelasticity of the hose material are considered. Thus, $C$ cannot be reckoned as a constant. Figure 3 illustrates the schematic considering the viscoelasticity of the hose.

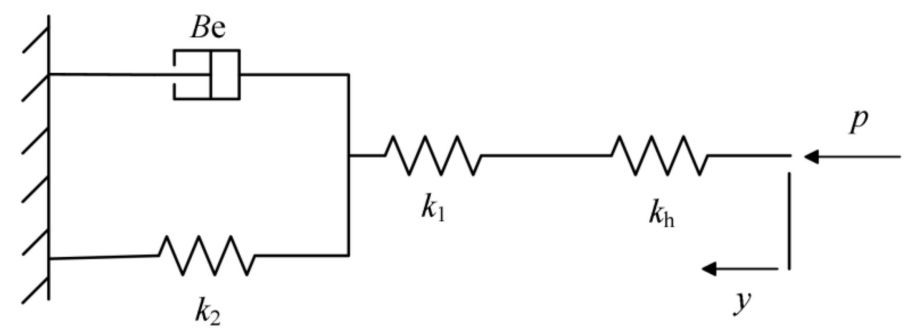

Figure 3. Viscoelastic model for hoses.

Ratio of $\Delta p$ to $\Delta y$ is related by

$$
\frac{\Delta p}{\Delta y}=k \cdot G(s)
$$

where

$$
\begin{gathered}
\frac{1}{k}=\frac{1}{k_{1}}+\frac{1}{k_{2}}+\frac{1}{k_{\mathrm{h}}} \\
k_{\mathrm{h}}=2 \beta_{\mathrm{e}} / a \\
G(s)=\frac{T_{1} s+1}{T_{2} s+1} \\
\left\{\begin{array}{c}
T_{1}=\frac{B e}{k_{2}} \\
T_{2}=\frac{B e}{k_{2}+k_{1} k_{2} /\left(k_{1}+k\right)}
\end{array}\right.
\end{gathered}
$$

Here, $p$ is the pressure inside the hose, $y$ is the radius variation of the hose, $k_{\mathrm{h}}$ is the equivalent coefficient of the oil compression converted into elastic deformation of the hose, $k_{1}$ and $k_{2}$ are the elastic coefficients of the hose and $B_{e}$ is the damping coefficient of the hose wall. $a$ is the average radius of the hose.

Increment of the flow rate $\Delta q$ can be written as

$$
\Delta q=\left(\pi(a+\Delta y)^{2}-\pi a^{2}\right) l=\left(2 \pi a \Delta y+\pi \Delta y^{2}\right) l
$$

where $l$ is the length of the hose. Neglecting $\pi \Delta y^{2}$, Equation (7) is simplified as

$$
\Delta q=2 \pi a \Delta y l=2 \pi a l \frac{\Delta p}{k \cdot G(s)}
$$

$C$ can be expressed as

$$
C=\frac{2 \pi a l}{k \cdot G(s)}
$$

Here, effects of the cylinder mass, leakage and oil temperature on the system are not considered. The pressure in two cylinders is assumed to be equal. Flow rate continuity for the actuation cylinder is given by

$$
\begin{aligned}
& A_{\mathrm{P} 1} \dot{X}_{\mathrm{pi}}-A_{\mathrm{A} 1} \dot{X}_{\mathrm{po}}=C \dot{P} \\
& A_{\mathrm{A} 2} \dot{\mathrm{X}}_{\mathrm{po}}-A_{\mathrm{P} 2} \dot{\mathrm{X}}_{\mathrm{pi}}=\dot{C}_{2}
\end{aligned}
$$

As shown in Figure $1, A_{\mathrm{P} 1}$ and $A_{\mathrm{P} 2}$ are the effective area of the power cylinder, $A_{\mathrm{A} 1}$ and $A_{\mathrm{A} 2}$ are the effective area of the target cylinder respectively. $X_{\mathrm{pi}}$ and $X_{\mathrm{po}}$ are the displacements of the power 
cylinder and the target cylinder, respectively. $V_{\mathrm{h} 1}$ is the pressurized volume enclosed by the hose connecting two rodless chambers and $V_{\mathrm{h} 2}$ is the one enclosed by the hose connecting two rod chambers.

The kinematic equation of the system is written as

$$
m \ddot{X}_{\mathrm{po}}=A_{\mathrm{A} 1} P_{1}-A_{\mathrm{A} 2} P_{2}-F-f_{\mathrm{v}}
$$

where $F_{\mathrm{t}}$ is the force as the external load, $m$ is the load mass, $P_{1}$ and $P_{2}$ are the pressure of the rod chamber and the rodless chamber of the target cylinder respectively, and $f_{\mathrm{v}}$ is the friction in the target cylinder as given by

$$
f_{\mathrm{v}}= \begin{cases}A_{\mathrm{A} 1} P_{1}-A_{\mathrm{A} 2} P_{2}-F, & \dot{X}_{\mathrm{po}}=0 \\ f_{\mathrm{s}}+\mu_{\mathrm{visc}} \dot{X}_{\mathrm{po}}, & \dot{X}_{\mathrm{po}} \neq 0\end{cases}
$$

where $f_{\mathrm{s}}$ is the maximum static friction and $\mu_{\mathrm{visc}}$ is the viscous friction coefficient.

$\dot{V}_{h 1}$ and $\dot{V}_{h 2}$ are obtained by Equation (1) as

$$
\left\{\begin{array}{l}
\dot{V}_{h 1}=C \dot{P}_{1} \\
\dot{V}_{h 2}=C \dot{P}_{2}
\end{array}\right.
$$

Based on Equation (10) to Equation (14), the mathematical model of the actuator system is established as

$$
\left\{\begin{array}{c}
m \ddot{X}_{\mathrm{po}}=A_{\mathrm{A} 1} P_{1}-A_{\mathrm{A} 2} P_{2}-F-f_{\mathrm{v}} \\
A_{\mathrm{P} 1} \dot{X}_{\mathrm{pi}}-A_{\mathrm{A} 1} \dot{X}_{\mathrm{po}}=C \dot{P}_{1} \\
A_{\mathrm{A} 2} \dot{X}_{\mathrm{po}}-A_{\mathrm{P} 2} \dot{X}_{\mathrm{pi}}=C \dot{P}_{2}
\end{array}\right.
$$

In order to evaluate the effects of the hose model qualitatively, the open-loop simulation results (taking input $=0.5 \mathrm{~m} / \mathrm{s}$ and $\mathrm{F}=200 \mathrm{~N}$ ) of the system with and without hose model are shown in Figure 4. It implies that the target cylinder displacement and the pressure in the rodless chamber with hose exhibits longer response lag during the system starts up.

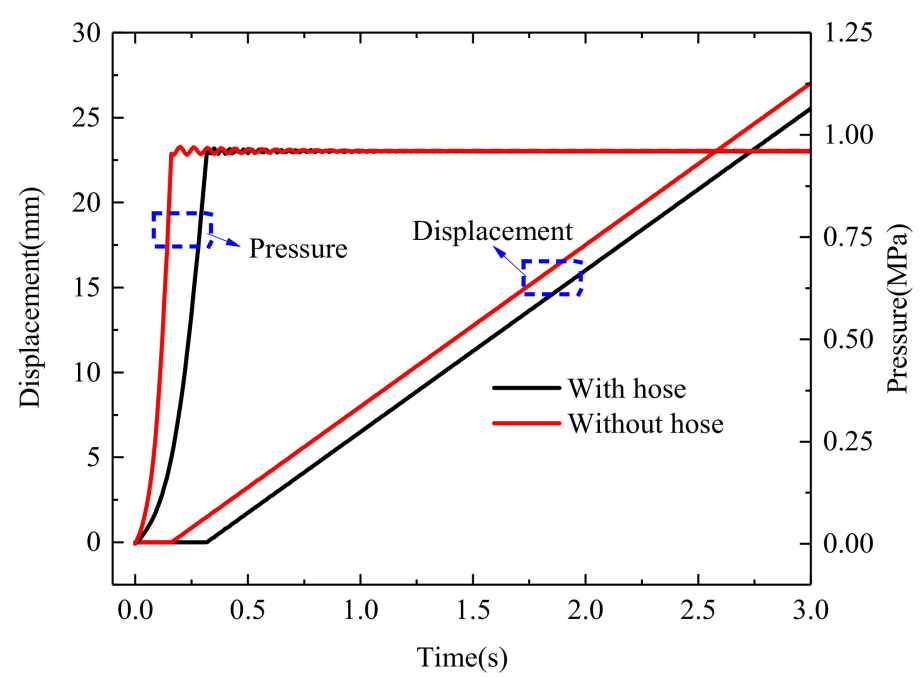

Figure 4. Displacement of the target cylinder and pressure in the rodless chamber.

\subsection{Controller Design}

The control principle of the system is shown in Figure 5. More specifically, the output $u$ of the controller is sent to the motor. Furthermore, the circular motion of the motor is converted to the linear motion of the power cylinder by the ball screw to drive the target cylinder. The position signal of the target cylinder is fed back to the controller by a LVDT. 


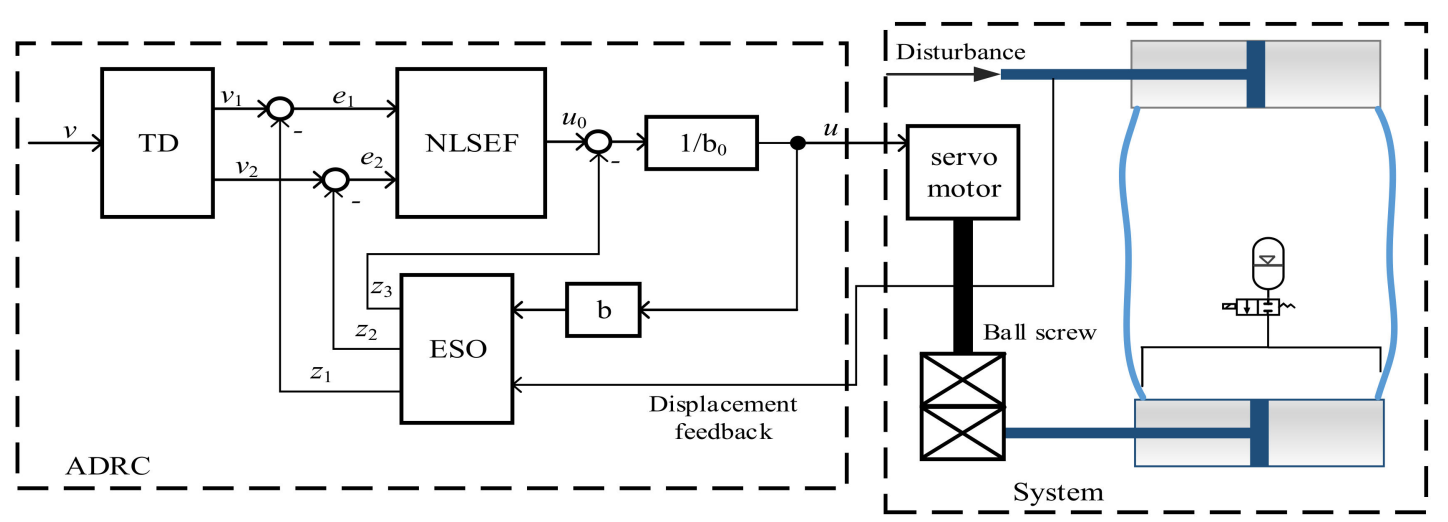

Figure 5. Schematic diagram based on active disturbance rejection control (ADRC).

\subsubsection{Tracking Differentiator (TD)}

In order to avoid noise amplification of traditional differential link, a TD achieves smooth approximation to the differential input, much superior to the traditional differential method in noise processing. The TD is mathematically defined by second-order equations as

$$
\left\{\begin{array}{l}
v_{1}(k+1)=v_{1}(k+1)+h v_{2}(k) \\
v_{2}(k+1)=v_{2}(k)+h \bullet \operatorname{fhan}\left(v_{1}(k)-v(k), v_{2}(k), r, h_{0}\right)
\end{array}\right.
$$

where $\operatorname{fhan}\left(v_{1}(k)-v(k), v_{2}(k), r, h_{0}\right)$ is the fastest control synthesis function of the system for building a discrete tracking differentiator.

$$
\begin{gathered}
d=r h_{0} \\
d_{0}=h_{0} d \\
y=v_{1}(k)-v(k)-h_{0} v_{2}(k) \\
a_{0}=\sqrt{d_{2}+8 r|y|} \\
a= \begin{cases}v_{2}(k)+\frac{\left(a_{0}-d\right)}{y} \operatorname{sign}(y), & |y|>d_{0} \\
v_{2}(k)+\frac{y_{0}}{h_{0}}, & |y| \leq d_{0}\end{cases} \\
\text { fhan }=- \begin{cases}r \frac{a}{d}, & |a| \leq d \\
r \operatorname{sign}(a), & |a|>d\end{cases}
\end{gathered}
$$

where $v$ and $v_{1}$ are the input and the output of the tracking differentiator, respectively, $v_{2}$ is the differential output of $v_{1}, r$ is the adjustable tracking speed, and $h$ and $h_{0}$ are the simulation intervals for the TD and fhan function, respectively. When $h=h_{0}$, the high-frequency oscillation in $v_{2}$ can be eliminated, and when $h>h_{0}$, the noise can be removed from $v_{2}$.

\subsubsection{Extended State Observer (ESO)}

As the core of the ADRC, the ESO estimates the total real-time disturbance of the system and transforms it into new state variables to compensate the controller output. Then, all the state variables are observed by using the input and output of the system. As described in Equation $(23), f\left(x_{1}, x_{2}, \omega(t), t\right)$ is added to the original system to make it expand into a new state variable.

$$
\left\{\begin{array}{l}
\dot{x}_{1}=x_{2} \\
\dot{x}_{2}=x_{3}+b u \\
\dot{x}_{3}=f\left(x_{1}, x_{2}, \omega(t), t\right) \\
y=x_{1}
\end{array}\right.
$$




$$
\left\{\begin{array}{l}
\varepsilon_{1}=z_{1}(k)-y(k) \\
z_{1}(k+1)=z_{1}(k)+h\left[z_{2}(k)-\beta_{01} \varepsilon_{1}\right] \\
z_{2}(k+1)=z_{2}(k)+h\left[z_{3}(k)-\beta_{02} f a l\left(\varepsilon_{1}, \alpha_{01}, \delta\right)+b_{0} u\right] \\
z_{3}(k+1)=z_{3}(k)-h \beta_{03} f a l\left(\varepsilon_{1}, \alpha_{02}, \delta\right)
\end{array}\right.
$$

where $z_{1}, z_{2}$ and $b_{0}$ are the estimations of $x_{1}, x_{2}$ and $b$, respectively. $z_{3}$ is the total disturbance estimation of the system. $\beta_{01}, \beta_{02}$ and $\beta_{03}$ are three constants in the ESO. fal $(x, \alpha, \delta)$ is the nonlinear function of the ESO.

$$
f a l(x, \alpha, \delta)= \begin{cases}x / \delta^{(1-\alpha)}, & |x| \leq \delta \\ |x|^{\alpha} \bullet \operatorname{sign}(x), & |x|>\delta\end{cases}
$$

\subsubsection{Nonlinear State Error Feedback (NLSEF)}

Based on the TD and the ESO, the error of the transition process can be tracked. The feedback control law is constructed by using nonlinear function $f a l(x, \alpha, \delta)$, so that the steady-state error decreases in the form of power function and the output response speeds up. The controller figures out its output according to the nonlinear combination of the difference between the estimated state variables and the real state variables as Equation (26)

$$
\begin{gathered}
\left\{\begin{array}{l}
e_{1}(k)=v_{1}(k)-z_{1}(k) \\
e_{2}(k)=v_{2}(k)-z_{2}(k)
\end{array}\right. \\
u_{0}(k)=\beta_{1} f a l\left(e_{1}(k), \alpha_{1}, \delta\right)+\beta_{2} f a l\left(e_{2}(k), \alpha_{2}, \delta\right)
\end{gathered}
$$

where $\beta_{1}$ and $\beta_{2}$ are the gain factors. $\alpha_{1}$ and $\alpha_{2}$ generally satisfy $0<\alpha_{1}<1<\alpha_{2}$.

The disturbance compensation in Equation (28) depends on the $\mathrm{ESO} z_{3}$ to estimate the total disturbance in real time.

$$
u(k)=\left(u_{0}(k)-z_{3}(k)\right) / b_{0}
$$

Actually the output $u(k)$ includes two parts: $-z_{3}(k) / b_{0}$ is the compensation disturbance component and $u_{0}(k)$ is the integrator series component controlled by the nonlinear feedback.

\section{Results}

Some preliminary experiments were implemented to verify the necessity of modeling the hose in this system. Figure 6 is the experimental system. Figure 7a shows the position of two cylinders for $5 \mathrm{~mm}$ command. The power cylinder moves $2.5 \mathrm{~mm}$ longer than the target cylinder in experiments. The simulated displacement of the power cylinder is smaller than the tested. It can be interpreted that the bubble in the pressurized oil and the cylinder leakage were not considered in this system. As a result of these two factors, the power cylinder moved longer to make the target cylinder close to the command displacement. Accordingly, the hose model obtained was workable. Figure $7 \mathrm{~b}$ depicts the position and the pressure of the target cylinder, with a step load and a motionless power cylinder.

Both figures prove that the volume change of the hose cannot be neglected when modeling the system and analyzing its behaviors.

To run a simulation, some parameters for the system and the designed controllers were summarized, as listed in Tables 1 and 2, respectively:

The step and sinusoidal tracking were set to verify the performance of the TD, as illustrated in Figure 8. It can be seen that the two output trajectories can track the input well. 


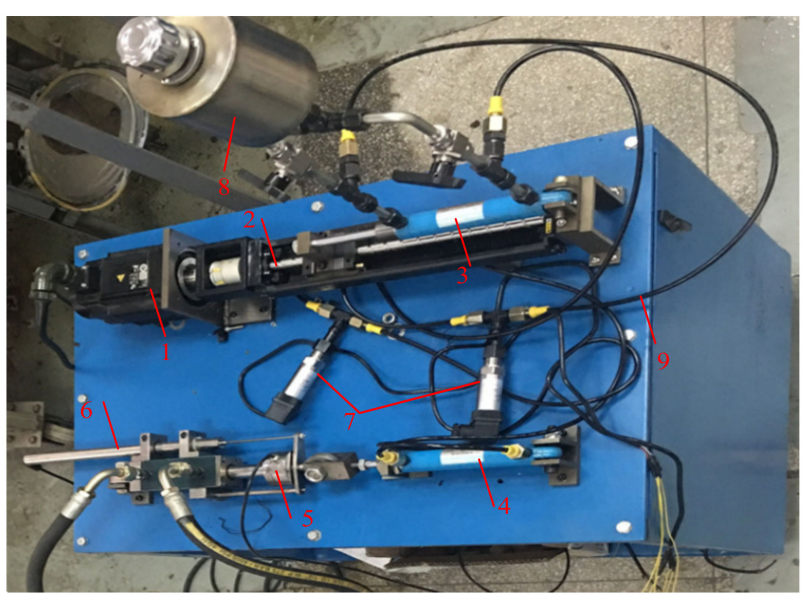

Figure 6. Experimental system.1. Stepping motor; 2. Ball screw; 3. Power cylinder; 4. Target cylinder; 5. Force transducer; 6. LVDT; 7. Pressure transducer; 8. Accumulator (oil compensation tank); 9. Hose.

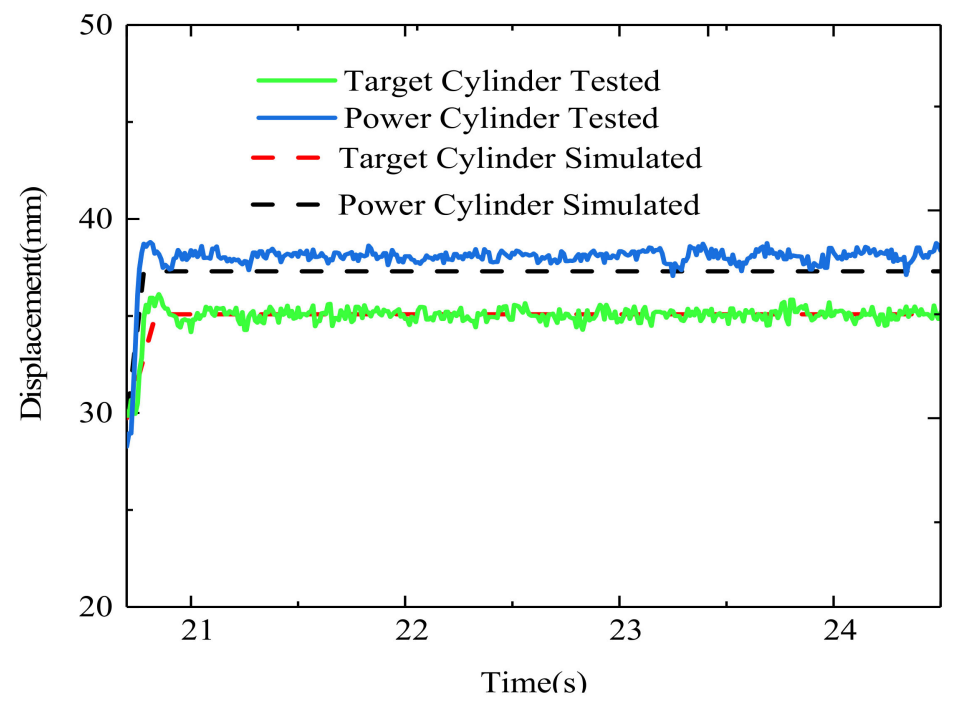

(a)

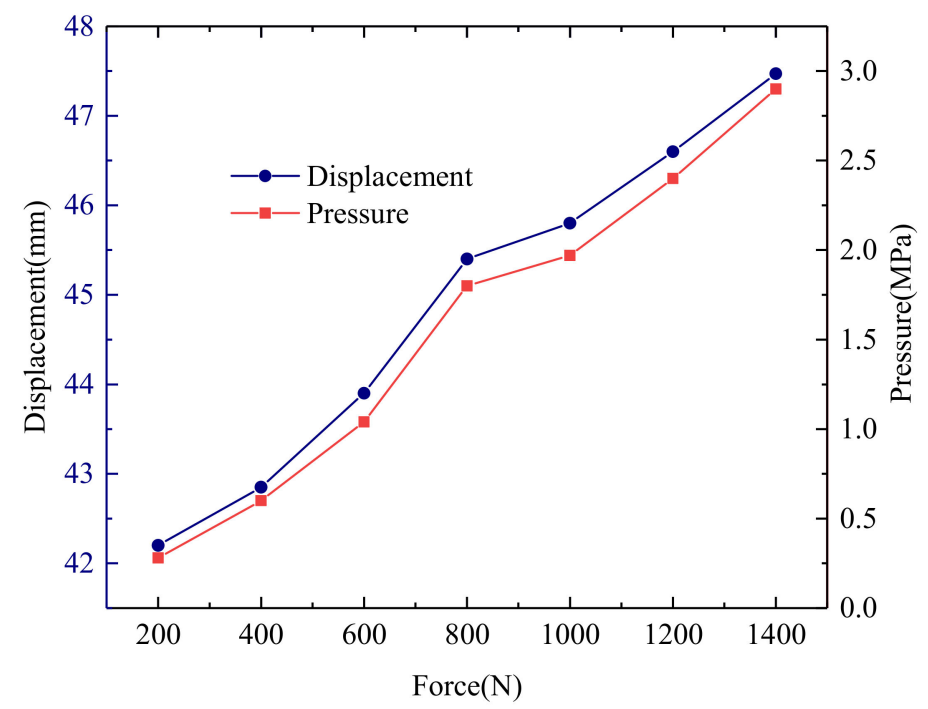

(b)

Figure 7. (a). Displacement of two cylinders. (b). Displacement of the target cylinder and pressure in the rodless chamber. 
Table 1. The servo system's parameters.

\begin{tabular}{cccccc}
\hline Parameter & Value & Parameter & Value & Parameter & Value \\
\hline$m$ & $50 \mathrm{~kg}$ & $r$ & $0.003 \mathrm{~m}$ & $c_{1}$ & 140 \\
$A_{P 1}$ & $3.77 \times 10^{-4} \mathrm{~m}^{2}$ & $l$ & $10 \mathrm{~m}$ & $\gamma_{1}$ & 0.5 \\
$A_{P 2}$ & $4.91 \times 10^{-4} \mathrm{~m}^{2}$ & $k_{11}$ & $6 \times 10^{5}$ & $c_{2}$ & 120 \\
$A_{A 1}$ & $3.14 \times 10^{-4} \mathrm{~m}^{2}$ & $k_{12}$ & 5000 & $\gamma_{2}$ & 0.1 \\
$A_{A 2}$ & $2.01 \times 10^{-4}$ & $k_{2}$ & $1 \times 10^{6}$ & $c_{\mathrm{j}}$ & {$[-1.0-0.500 .51]$} \\
$f_{s}$ & $50 \mathrm{~N}$ & $\mu_{\text {visc }}$ & $200 \mathrm{~N} \cdot \mathrm{s} / \mathrm{m}$ & $b_{\mathrm{j}}$ & 5 \\
\hline
\end{tabular}

Table 2. The controller's parameters.

\begin{tabular}{cccccc}
\hline Parameter & Value & Parameter & Value & Parameter & Value \\
\hline $\mathrm{P}$ & 7 & $\beta_{02}$ & 100 & $\alpha_{2}$ & 0.4 \\
$\mathrm{I}$ & 0.01 & $\beta_{03}$ & 30 & $b_{0}$ & 0.02 \\
$h$ & 0.002 & $\beta_{1}$ & 50 & $b$ & 5 \\
$h_{0}$ & 0.002 & $\beta_{2}$ & 0.1 & $r$ & 0.005 \\
$\beta_{01}$ & 50 & $\alpha_{1}$ & 0.5 & $\delta$ & 0.001 \\
\hline
\end{tabular}

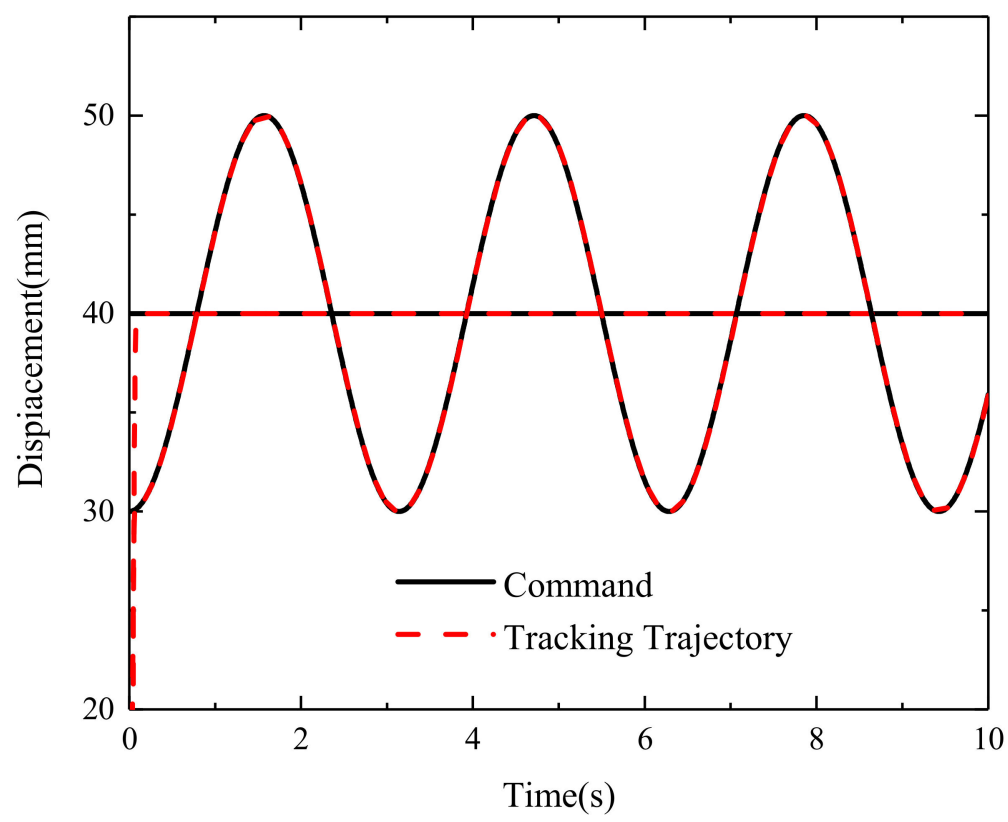

Figure 8. Step and sinusoidal tracking displacement.

Comparison of the results with three controllers is demonstrated in Figure 9, with the step response to $50 \mathrm{~mm}$ input command with a step load ( $800 \mathrm{~N}$ at $4 \mathrm{~s}$ and $400 \mathrm{~N}$ at $7 \mathrm{~s}$ ). It was seen that the displacement response with ADRC at the beginning was faster, achieving steady state in shorter time (stabilizing the output nearly for $0.15 \mathrm{~s}$ by ADRC while $1 \mathrm{~s}$ by PID or fuzzy PID). As shown in Figure 10, compared with the PID controller and the fuzzy PID controller, the target cylinder with ADRC had smaller error because the ADRC produced a faster and higher-amplitude control signal when the step load interfered with the system output to make the system respond more quickly and reduce the influence of the disturbance on the system. The ADRC used an ESO to obtain the observation of the state variables and disturbances. As shown in Figure 11, the observation results were consistent with the actual items. 


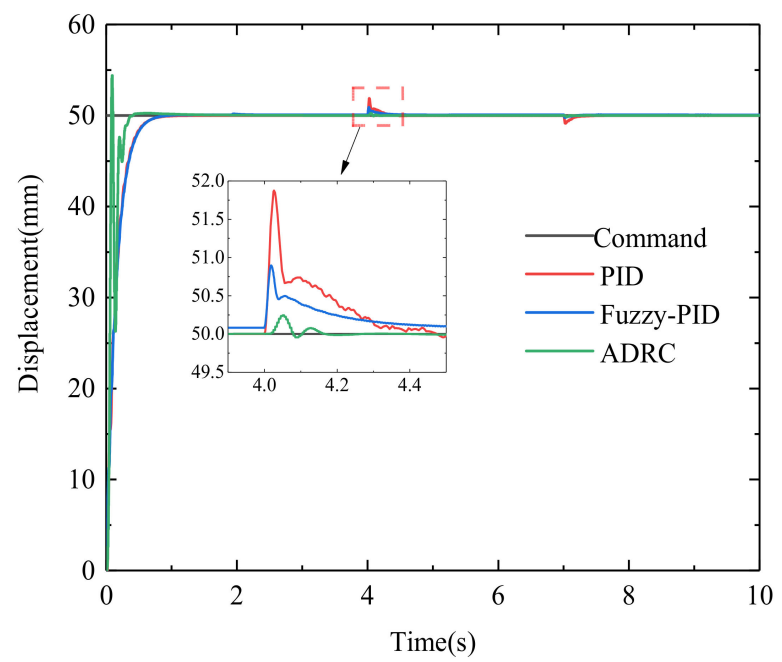

Figure 9. Response to step load.

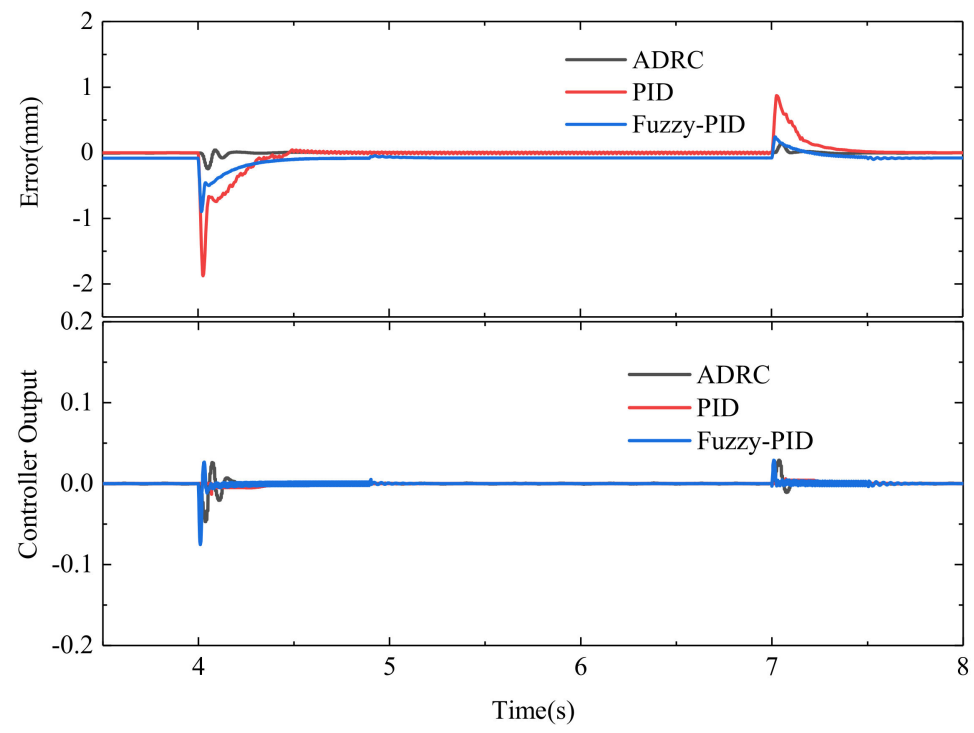

Figure 10. Error and controller output.

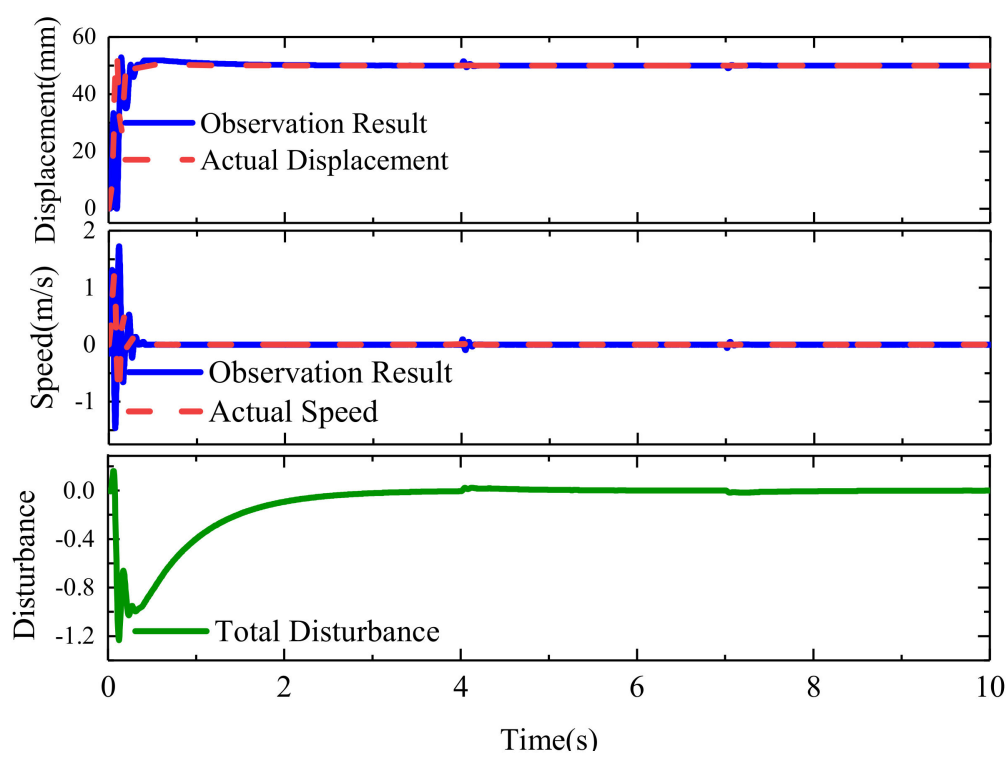

Figure 11. Observations made by extended state observer. 
Figure 12 illustrates that, when the displacement command stepped from $0 \mathrm{~mm}$ to $50 \mathrm{~mm}$, the system using PID control or fuzzy PID control exhibited slower adjustment and less smoothness. The system with ADRC facilitated faster and smoother adjustment to the input. Figure 13 is the phase path for the displacement error at $4 \mathrm{~s}$ to $5 \mathrm{~s}$. It implies that the ADRC controller enabled better synthetic control performance than the PID controller or fuzzy PID controller.

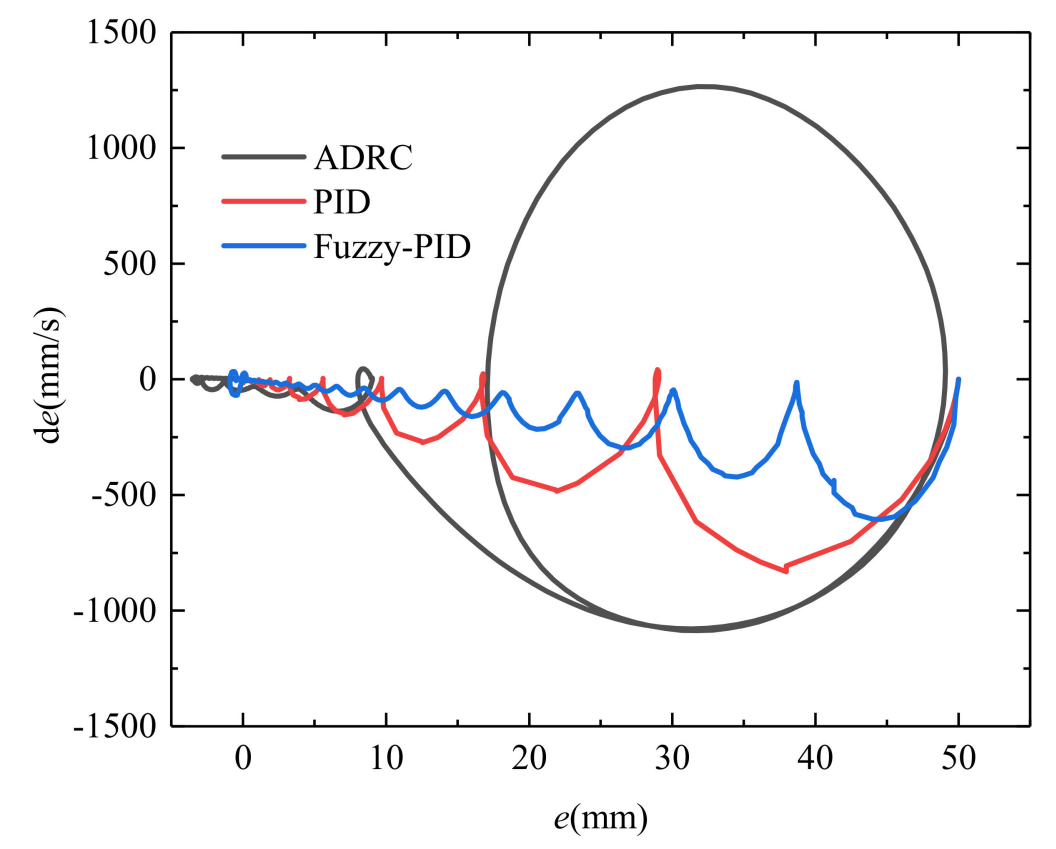

Figure 12. Phase path for the displacement error from $0 \mathrm{~mm}$ to $50 \mathrm{~mm}$.

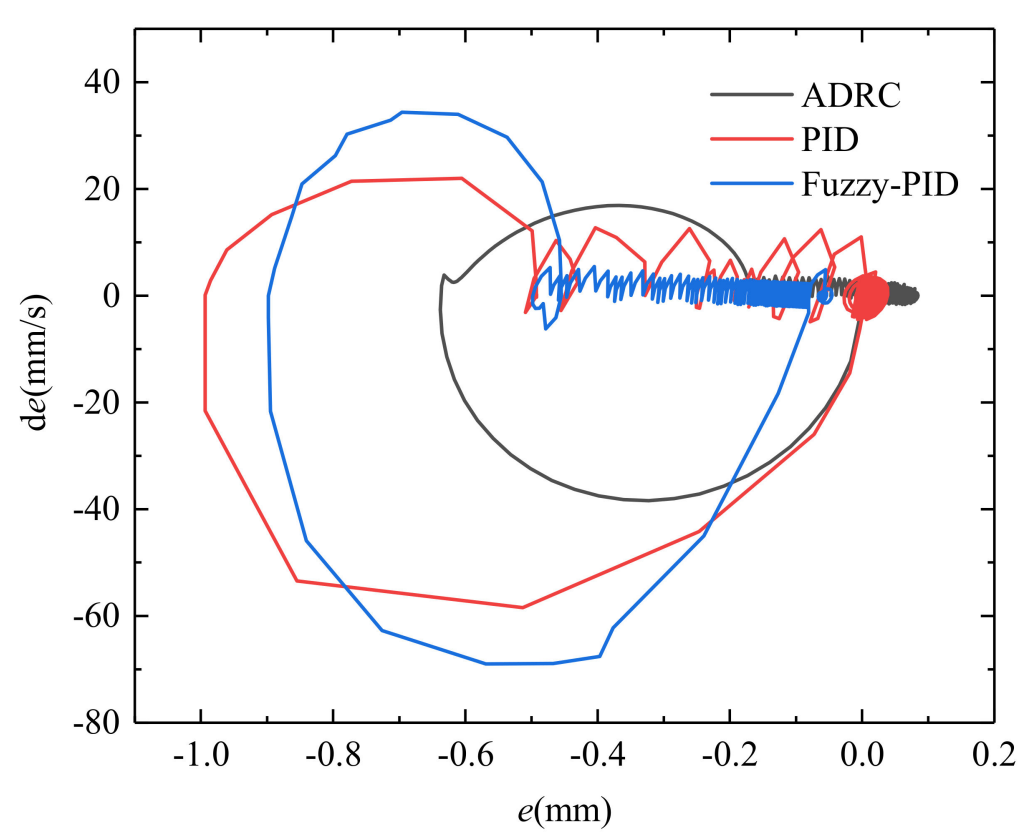

Figure 13. Phase path for the displacement error from $4 \mathrm{~s}$ to $5 \mathrm{~s}$.

Figure 14 depicts the step response under a sinusoidal load $(\mathrm{Ft}=100 \sin (\pi \mathrm{t}+500 \mathrm{~N})$. The steady-state error of the system using ADRC is smaller than that using the PID, indicating that ADRC has better robustness. The output of the two controllers is illustrated in Figure 15. The output of the ADRC is similar to the PID controller, The ADRC has similar output to the PID controller, but the control performance of the system using the ADRC is better. Thus, it reflects the advantages of ADRC 
on robustness. Figure 16 shows the estimated speed, displacement and total disturbance of the target cylinder via the ESO. Its observation value is basically qualified and can lay a foundation of high-performance control to analogous uncertain systems.

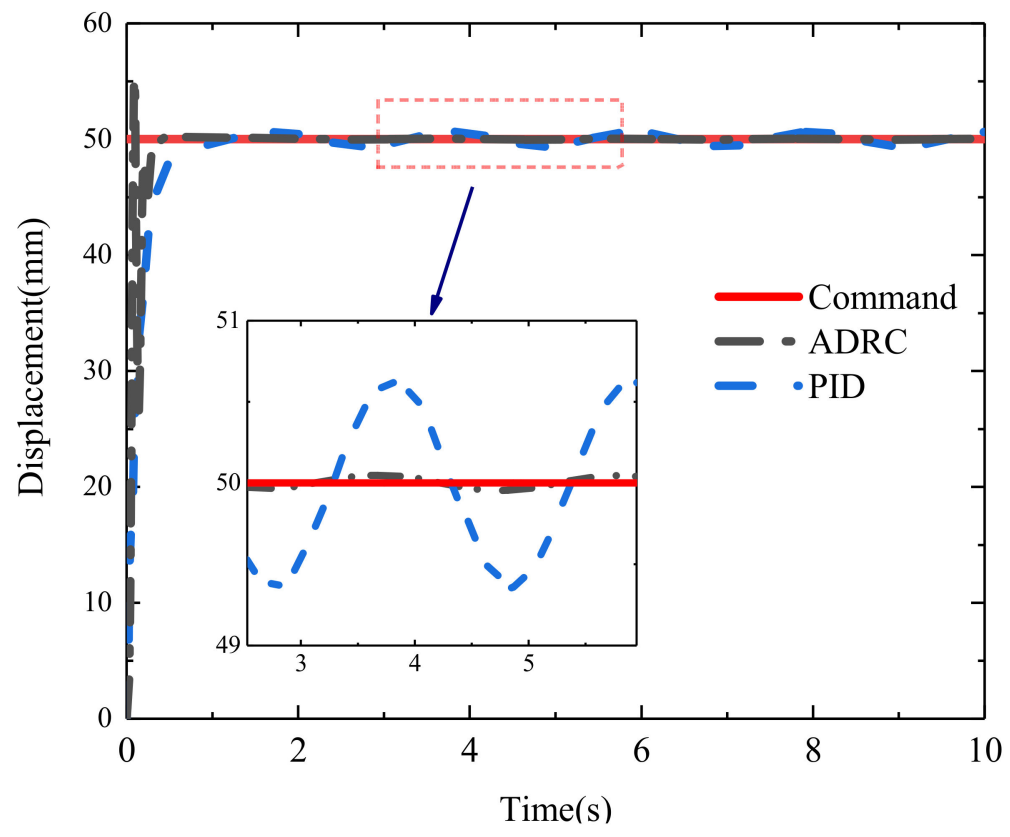

Figure 14. Response to a sinusoidal load.

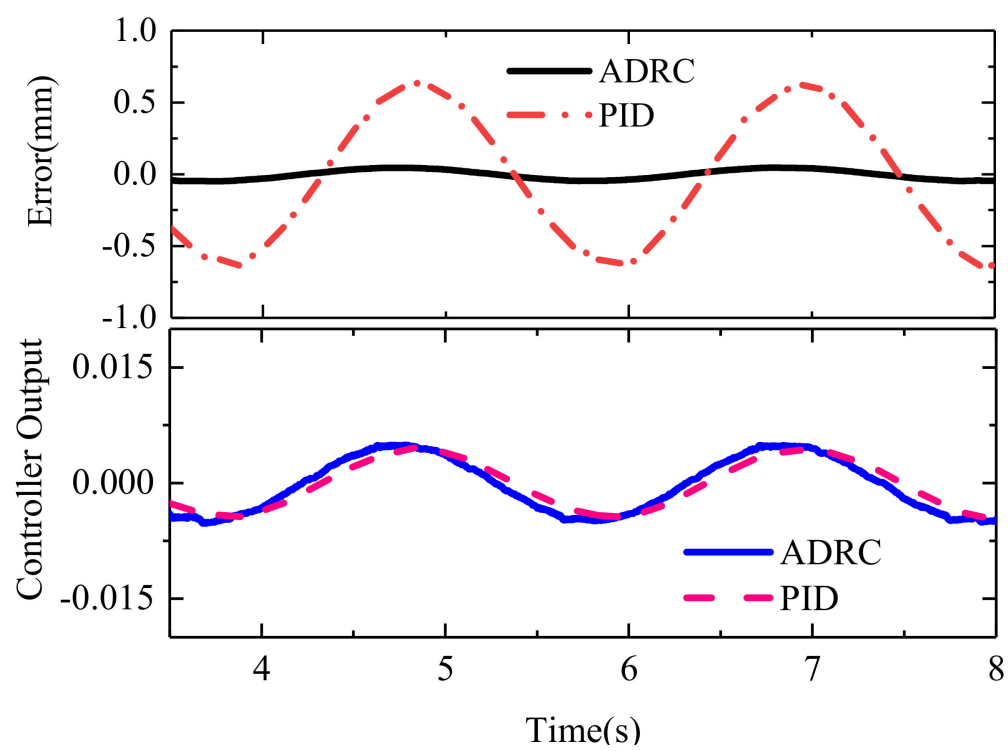

Figure 15. Error and controller output.

In order to further study the tracking performance and robustness of the ADRC, simulation for the sinusoidal tracking was carried out. Figure 17 shows the output at a sinusoidal input without load. It reveals that the system using the ADRC tracked the input well, while that using PID had a lag. Figure 18 depicts the sinusoidal response of the system under a constant load. The ADRC facilitated the output tracking and the PID control tended to result in a considerable lag. In Figure 19, the output of the PID controller was smoother, and it had advantages over the ADRC in engineering implementation, so it could reduce the wastage of the motor. Figure 20 demonstrates that the estimated state variables and total interference were also consistent with the actual results. Generally, the system with ADRC had better tracking effects and robustness under constant force disturbance. 


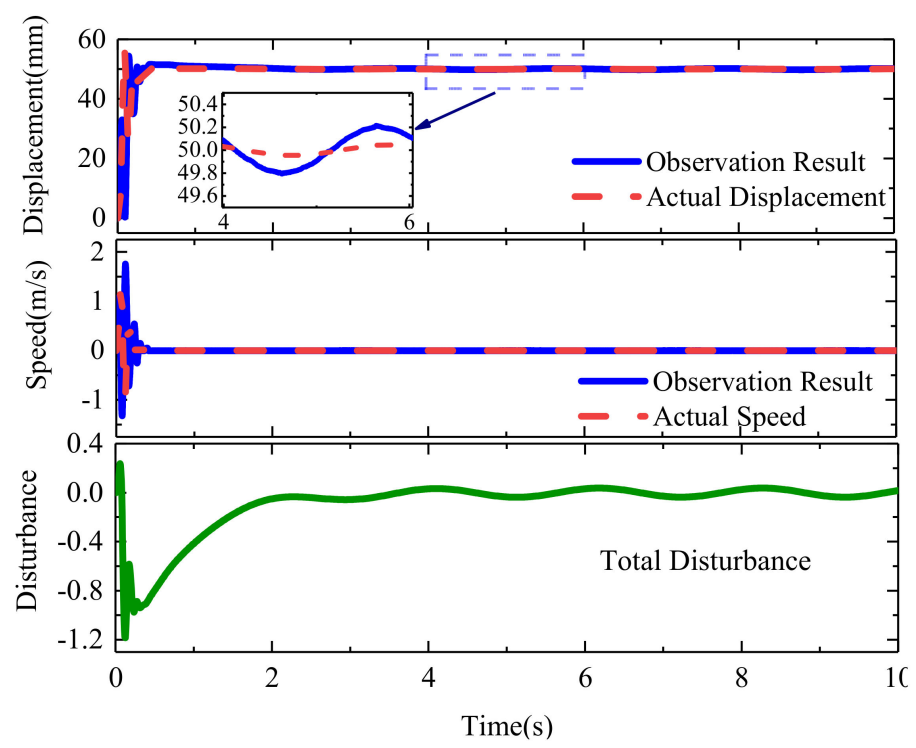

Figure 16. Observations by the ESO.

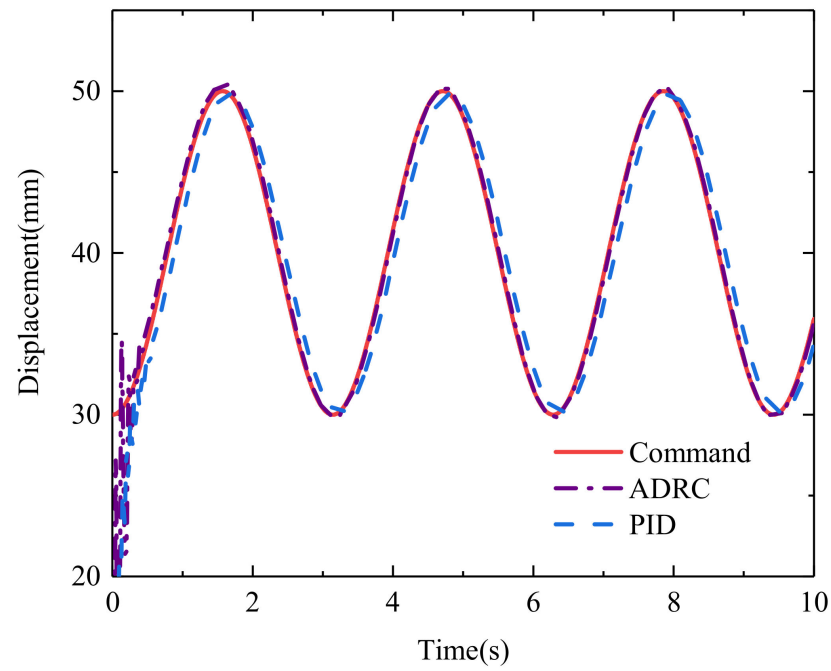

Figure 17. Sinusoidal response.

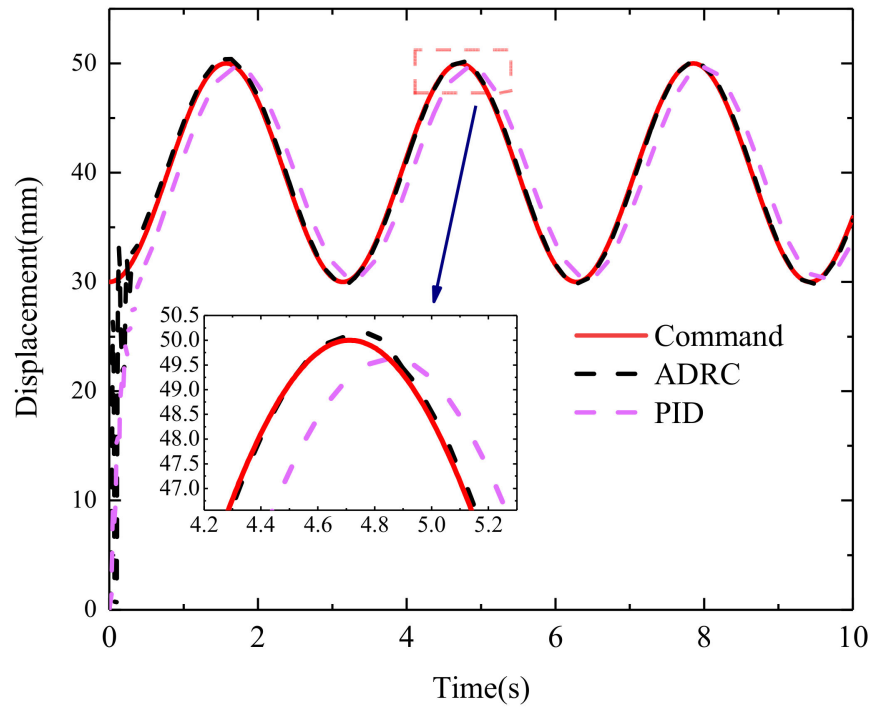

Figure 18. Responses to constant load. 


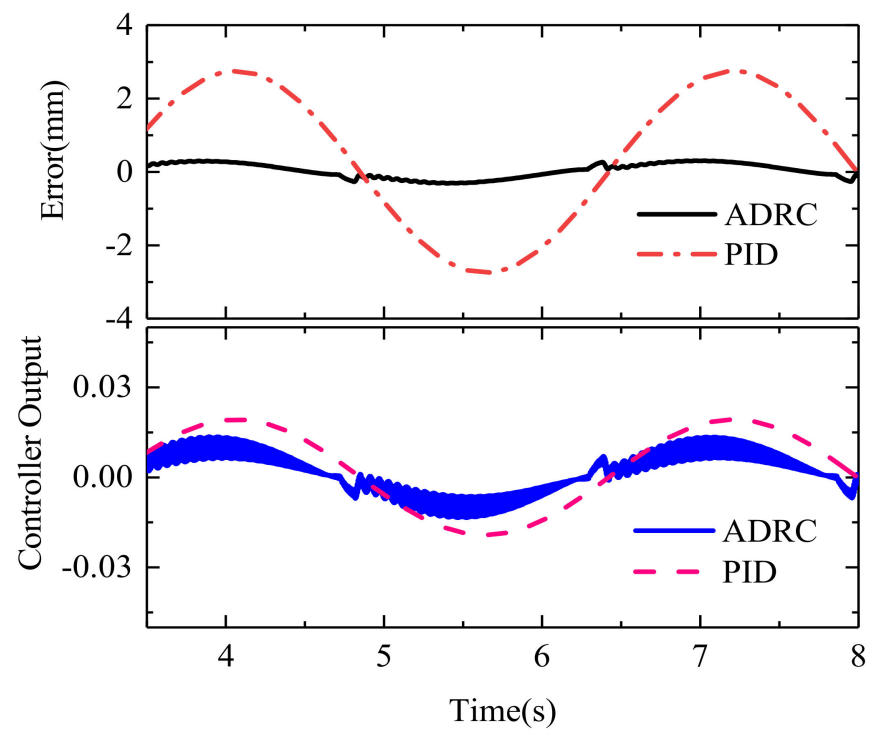

Figure 19. Error and controller output.

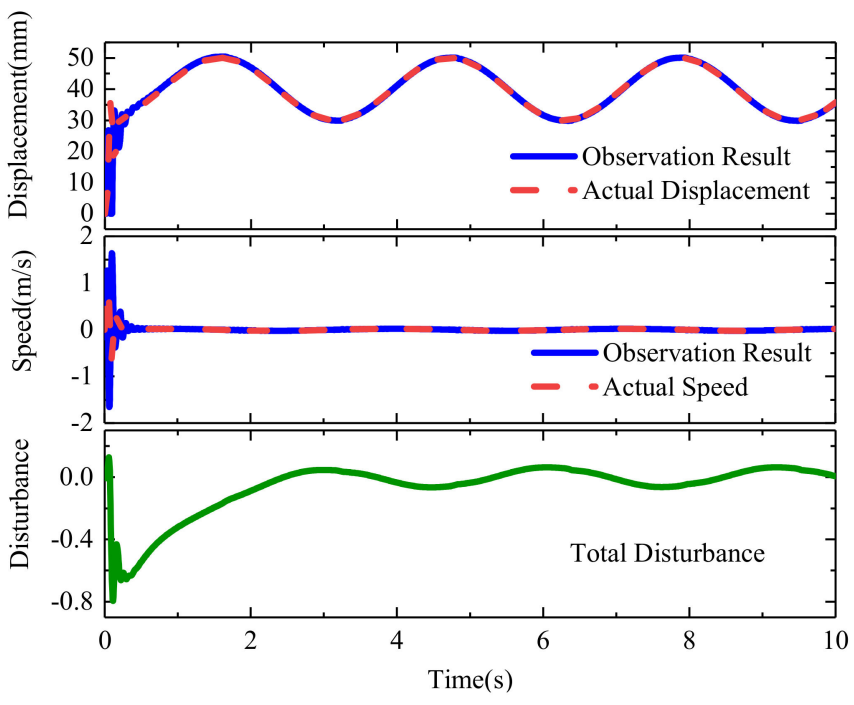

Figure 20. Observations by ESO to constant load.

Figure 21 depicts the system output at a sinusoidal input under a random load. It reveals that the system using PID and fuzzy PID had a certain lag than that using ADRC. As shown in Figure 22, the system using ADRC also had better tracking effect and robustness under random load interference, compared with that using PID controller or fuzzy PID controller. Figure 22 implies that the ADRC produced high-amplitude output, but there was a certain oscillation in the controller output. Figure 23 shows the estimated states and total disturbance. The analysis above indicates that the ADRC enabled faster response and higher accuracy for the actuation. Additionally, the disturbance and uncertain parameters estimated by the ESO substantially enhanced the system robustness. 


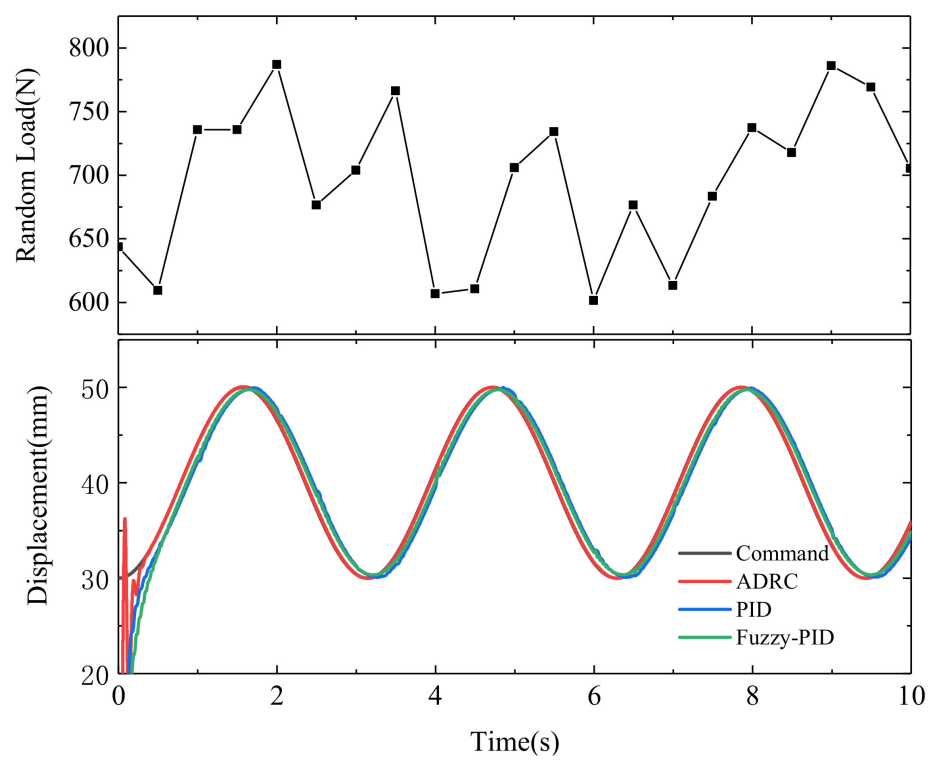

Figure 21. Responses to random load.

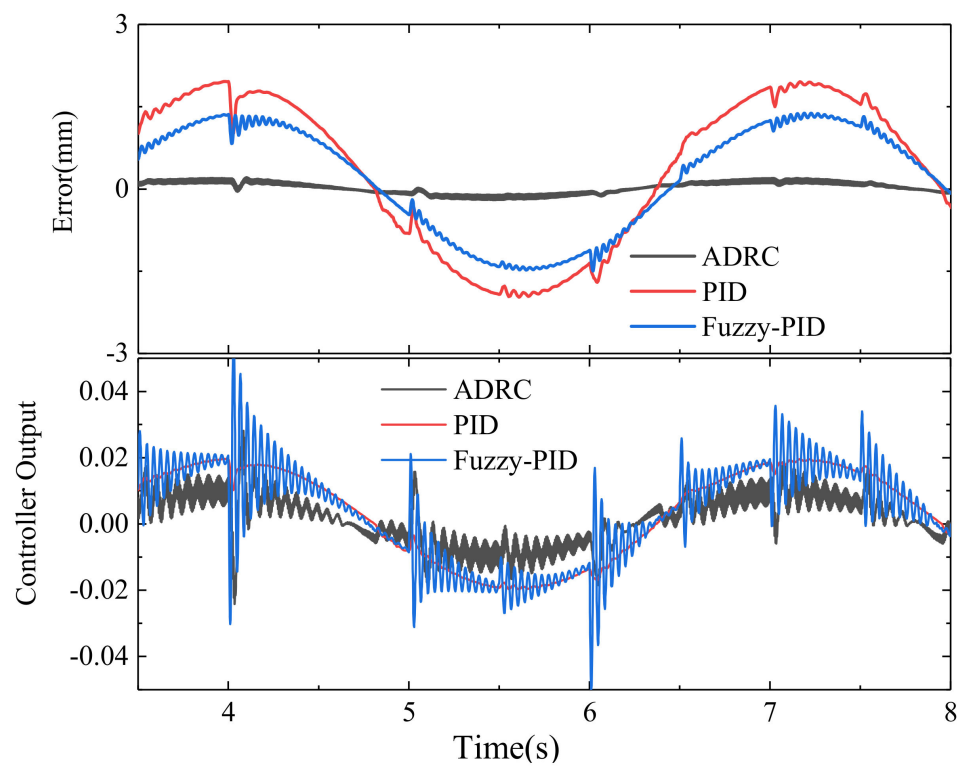

Figure 22. Error and controller output.

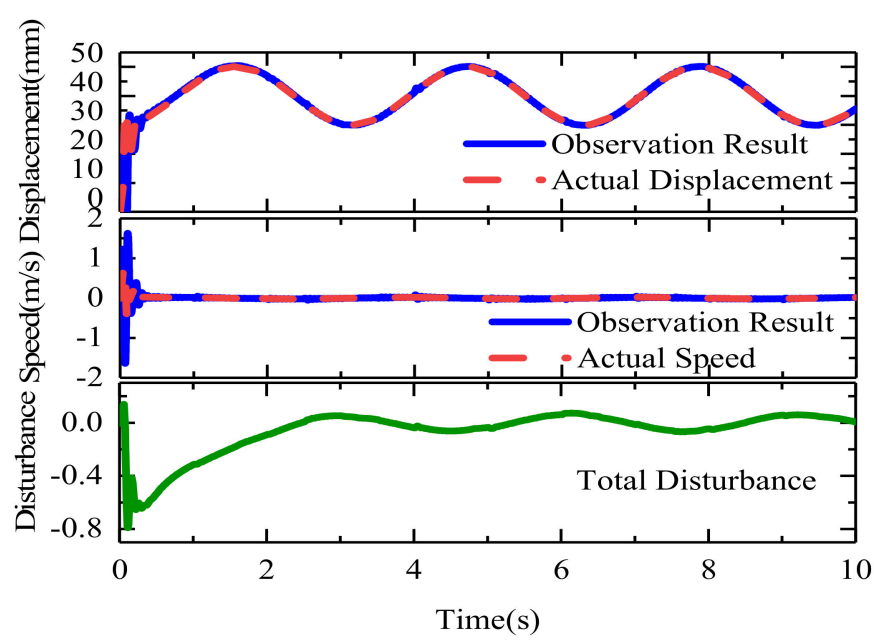

Figure 23. Observations made by extended state observer. 


\section{Conclusions}

In this paper, an ADRC strategy is proposed for the double-cylinder hydrostatic actuator to improve the dynamic and steady performance in the presence of uncertain model parameters and external load. The mathematical modeling and simulations were executed to verify the effects of the ADRC on the system. Considering elastic deformation, the hose used in the system was modeled by dint of the centralized parameter method. Under a step and sinusoidal command without load, the system which used ADRC had higher accuracy and better dynamic performance than that which used the conventional PID or fuzzy PID. In terms of anti-interference, the system which used the ADRC was superior to the other two systems. Although for a sinusoidal command, the output of the PID controller was smoother, the disturbance rejection ability of the ADRC was better. In contrast, the ADRC had stronger robustness and superior output, which can provide some guidance for engineering practice.

Author Contributions: B.W. performed the experimental investigation. H.J. built the mathematical model and analyzed the simulation data. B.W. wrote the paper. H.J. and R.C. contributed to the discussion of the results. All authors have read and agreed to the published version of the manuscript.

Funding: This study was financially supported by the Natural Science Foundation of Jiangsu Province (Grant No BK20171412), and partially by the National Natural Science Foundation of China (Grant No 51575257).

Conflicts of Interest: The authors declare no conflict of interest.

\section{References}

1. Chao, Q.; Zhang, J.; Xu, B.; Huang, H.; Pan, M. A Review of High-Speed Electro-Hydrostatic Actuator Pumps in Aerospace Applications: Challenges and Solutions. J. Mech. Des. 2019, 141, 050801-1. [CrossRef]

2. Kim, J.-H.; Hong, Y.-S. Improvement of Backdrivability of a Force-Controlled EHA by Introducing Bypass Flow Control. Int. J. Precis. Eng. Manuf. 2020, 21, 819-830. [CrossRef]

3. Fu, Y.; Han, X.; Sepehri, N.; Zhou, G.; Fu, J.; Yu, L.; Yang, R. Design and performance analysis of position-based impedance control for an electrohydrostatic actuation system. Chin. J. Aeronaut. 2018, 31, 584-596. [CrossRef]

4. Ahn, K.K.; Nam, D.N.C.; Jin, M. Adaptive Backstepping Control of an Electrohydraulic Actuator. IEEE/ASME Trans. Mechatron. 2013, 19, 987-995. [CrossRef]

5. Dong, L.; Yan, H.; Feng, L.; Tan, Q. Modelling and performance analysis of designed energy-efficient eha under gravity loads. Internat. J. Model. Identificat. Control 2018, 30, 253-260. [CrossRef]

6. Minav, T.; Pietola, M.; Filatov, D.M.; Devyatkin, A.V.; Heikkinen, J. Fuzzy control of direct-driven hydraulic drive without conventional oil tank. In Proceedings of the 2017 XX IEEE International Conference on Soft Computing and Measurements (SCM), St. Petersburg, Russia, 24-26 May 2017; Institute of Electrical and Electronics Engineers (IEEE): Piscataway, NJ, USA, 2017; pp. 444-447.

7. Minav, T.; Heikkinen, J.; Schimmel, T.; Pietola, M. Direct Driven Hydraulic Drive: Effect of Oil on Efficiency in Sub-Zero Conditions. Energies 2019, 12, 219. [CrossRef]

8. Hyvärinen, J.; Karlsson, M.; Zhou, L. Study of concept for hydraulic hose dynamics investigations to enable understanding of the hose fluid-structure interaction behavior. Adv. Mech. Eng. 2020, 12, 1-18. [CrossRef]

9. Farong, K.; Zhe, W.; Jiafeng, D.U.; Dong, L.I.; Jianan, X.U.; Linglan, H.E. Study on force tracking control of eha active suspensions. China Mech. Eng. 2017, 28, 2964-2970. [CrossRef]

10. João, F.C.; João, B.P.; Fernando, G.A. Accurate motion control of a pneumatic linear peristaltic actuator. Actuators 2020, 9, 63. [CrossRef]

11. Hao, W.; Kan, J. Application of self-tuning fuzzy proportional-integral-derivative control in hydraulic crane control system. Adv. Mech. Eng. 2016, 8, 1-10. [CrossRef]

12. Truong, D.Q.; Ahn, K.K. Force control for hydraulic load simulator using self-tuning grey predictor-Fuzzy PID. Mechatronics 2009, 19, 233-246. [CrossRef]

13. Ahn, K.K.; Truong, D.Q.; Thanh, T.Q.; Lee, B.R. Online self-tuning fuzzy proportional—Integral—Derivative control for hydraulic load simulator. Proc. Inst. Mech. Eng. Part I J. Syst. 2008, 222, 81-95. [CrossRef]

14. Ye, Y.; Yin, C.-B.; Gong, Y.; Zhou, J.-J. Position control of nonlinear hydraulic system using an improved PSO based PID controller. Mech. Syst. Signal Process. 2017, 83, 241-259. [CrossRef]

15. Esfandiari, M.; Sepehri, N.; Esfandiari, M. Controller Design and Stability Analysis of Output Pressure Regulation in Electrohydrostatic Actuators. J. Dyn. Syst. Meas. Control. 2018, 141, 041008. [CrossRef] 
16. Erik, E.; Georg, B.; Nathan, M. Analysis of the influence of suspension actuator limitations on ride comfort in passenger cars using model predictive control. Actuators 2020, 9, 77. [CrossRef]

17. Yang, R.; Fu, Y.; Zhang, L.; Qi, H.; Han, X.; Fu, J. A Novel Sliding Mode Control Framework for Electrohydrostatic Position Actuation System. Math. Probl. Eng. 2018, 2018, 1-22. [CrossRef]

18. Bone, G.M.; Xue, M.; Flett, J. Position control of hybrid pneumatic-electric actuators using discrete-valued model-predictive control. Mechatronics 2015, 25, 1-10. [CrossRef]

19. Yang, G.; Yao, J. Output feedback control of electro-hydraulic servo actuators with matched and mismatched disturbances rejection. J. Frankl. Inst. 2019, 356, 9152-9179. [CrossRef]

20. Castañeda, L.; Luviano-Juárez, A.; Ochoa-Ortega, G.; Chairez, I. Tracking control of uncertain time delay systems: An ADRC approach. Control. Eng. Pr. 2018, 78, 97-104. [CrossRef]

21. $\mathrm{Wu}, \mathrm{Y}$; Zheng, Q. ADRC or adaptive controller-A simulation study on artificial blood pump. Comput. Biol. Med. 2015, 66, 135-143. [CrossRef] [PubMed]

22. Xue, W.; Bai, W.; Yang, S.; Song, K.; Huang, Y.; Xie, H. ADRC with Adaptive Extended State Observer and its Application to Air-Fuel Ratio Control in Gasoline Engines. IEEE Trans. Ind. Electron. 2015, 62, 5847-5857. [CrossRef]

23. Zhu, E.; Pang, J.; Sun, N.; Gao, H.; Sun, Q.; Chen, Z. Airship horizontal trajectory tracking control based on Active Disturbance Rejection Control (ADRC). Nonlinear Dyn. 2013, 75, 725-734. [CrossRef]

24. Wu, Z.-H.; Guo, B.-Z. Approximate decoupling and output tracking for MIMO nonlinear systems with mismatched uncertainties via ADRC approach. J. Frankl. Inst. 2018, 355, 3873-3894. [CrossRef]

25. Aboudrar, I.; el Hani, S.; Heyine, M.S.; Naseri, N. Dynamic Modeling and Robust Control by ADRC of Grid-Connected Hybrid PV-Wind Energy Conversion System. Math. Probl. Eng. 2019, 2019, 1-19. [CrossRef]

26. Liu, C.; Luo, G.; Chen, Z.; Tu, W.; Qiu, C. A linear ADRC-based robust high-dynamic double-loop servo system for aircraft electro-mechanical actuators. Chin. J. Aeronaut. 2019, 32, 2174-2187. [CrossRef]

27. Tian, Y.; Liu, B.; Gao, H.W.; Li, W.Q. Modeling and Simulation of Electro-Hydraulic Proportional Position Control System with the Flexible Hose. Adv. Mater. Res. 2012, 468, 2094-2099. [CrossRef]

Publisher's Note: MDPI stays neutral with regard to jurisdictional claims in published maps and institutional affiliations.

(C) 2020 by the authors. Licensee MDPI, Basel, Switzerland. This article is an open access article distributed under the terms and conditions of the Creative Commons Attribution (CC BY) license (http://creativecommons.org/licenses/by/4.0/). 